\section{The monaural localization of tonal stimuli*}

\author{
ROBERT A. BUTLER \\ Department of Surgery (Otolaryngology), University of Chichgo, Chicago, Illinois 60637
}

With one ear occluded, 17 listeners were asked to locate tone bursts, $.25, .4, .6, .9,1.4$, $2.0,3.2,4.8$, and $7.2 \mathrm{kHz}$, generated by a loudspeaker concealed from view. The S's response was to call out that number, from a series of numbers arranged horizontally, behind which he thought the tone bursts originated. The listeners perceived the sounds as emanating from the side of the unoccluded ear, but their judgments bore no consistent relation to the actual location of the sound source. Rather, the listeners showed a strong tendency to locate a tone burst, within the range of .9 through $7.2 \mathrm{kHz}$, in a fixed spatial relation to the next higher- and lower-pitched tone burst. Disturting the pinna of the unoccluded ear failed to modify the perceptual pattern. It was suggested that the perceived spatial relations among the various frequencies was a by-product of the tonotopic organization of the auditory nervous system.

"The more nearly the sounds approach pure tones, the more inaccurate the localization. This is true regardless of the absolute pitch. Genuinely pure tones are essentially unlocalizable in monaural hearing [Angell \& Fite, 1901, p. 245]." So concluded the authors after testing extensively with a variety of sounds the localizing ability of a unilaterally deaf person. Their statement should have been qualified, since the listener did assign 72 out of 90 sounds presented by tuning forks to a specific position in space. It was only that his choices were usually wrong. Whether he systematically positioned those tones with respect to their pitch cannot be deduced from the description of the data. This does occur, however, when the sounds originate in the vertical plane, directly ahead of the listener. High-pitched tones are perceived to originate above lower-pitched tones (Pratt, 1930). In both the Angell and Fite and the Pratt studies, the cues for binaural time and intensity differences were absent; hence, listeners were deprived of the information necessary for distinguishing between the locations of the sound sources. The fact that Pratt's listeners located higher-pitched sounds in the vertical plane above lower-pitched sounds could have been the result of extrinsic associations. We use the words "high" and "low" when describing the pitch of a sound. In the absence of binaural cues for spatial position, these word associations may cause us to perceive sinusoids with brief periods as high, and those with longer periods as low in space. On the other hand, the correct interpretation of this phenomenon may be just the opposite; i.e., we use the words "high" and "low" to refer to the pitch of

*This work was supported by USPHS Clinical Research Center Grant NS 03358-09 and a Research Career Development Award from NINDS. tones because tonal stimuli of differing frequencies do indeed appear spatially differentiated in this way in the vertical plane. Some data support this suggestion. Roffler and Butler (1968), studying vertical plane localization, reported that children 4 and 5 years old perceived high-pitched tones as emanating above low-pitched tones. During posttest conversations the children gave no indication of associating the words "high" and "low" with the stimulus frequency.

The present paper explores this problem further. An experiment was designed to find out whether a systematic spatial relation among various tonal frequencies exists when listeners, deprived of binaural cues, are asked to locate these stimuli in the horizontal plane. Positive results, should they occur, could not be explained in terms of word association. The words "high" and "low" obviously are not applicable to this type of listening situation; nor are any other words associated with tonal frequencies likely to influence the perception of their relative position in the horizontal plane.

\section{PILOT STUDY}

\section{Method}

Five listeners participated. Their audiometric thresholds for frequencies ranging from .25 through $8.0 \mathrm{kHz}$ were within $15 \mathrm{~dB}$ of 0 re ISO standards. The listeners were seated comfortably at the center of a semicircular reinforced screen whose radius was $5 \mathrm{ft}$. Nine $K L H$ loudspeakers, 4-in. diam, were attached to the screen at eye level. Each was housed in a wooden cabinet, $6.25 \times 6.25 \times 4$ in., and was identified by a number, 1 through 9 , according to its horizontal position on the screen. With reference to the vertex of the listener's head, the speakers were placed 10 deg apart, center to center.

Before testing, a Mine Safety Appliance ear insert was fitted inside one ear canal of the $S$ and a Mine Safty Appliance Muff (Noisefoe Mark IIM) was placed over the same ear. The ear chosen for occlusion was on the side of the nonpreferred hand. After occlusion, thresholds for the tone bursts of $.25, .4, .6, .9,1.4,2.0,3.2,4.8$, and $7.2 \mathrm{kHz}$ were obtained. These stimuli, whose rise-fall time was $5 \mathrm{msec}$ and whose plateau was $10 \mathrm{msec}$, were repeated approximately six times per second. Following threshold measurements, Ss were instructed to call out the number of the loudspeaker from which the tone bursts appeared to originate. They were requested to keep their heads firmly in the headrest that was attached to the chair. Each $S$ was oriented so that the array of loudspeakers extended from directly ahead to $80 \mathrm{deg}$ toward the side of his unoccluded ear. Only loudspeakers at 10 , 30,50 , and $70 \mathrm{deg}$ from the S's median sagittal plane were used, although the listeners were not aware of this restriction Each of the nine frequencies was generated three times by each of the four loudspeakers. Hence, every frequency was presented 12 times and the test session consisted of 108 tonal presentations, or trials. Orders of presentation for loudspeakers and frequencies were quasirandom. Tone bursts were delivered at 20 phons and continued until the listener made a location judgment. Testing was conducted in a sound-treated room with the sound-generating equipment (Krohn-Hite oscillator, Grason-Stadler electronic switch and interval timer) located in an adjoining room. An intercom system served to maintain voice contact between $S$ and $E$.

\section{Results}

Upon inspection of the data, there was no indication that Ss were locating sound sources with an accuracy exceeding chance. However, a definite pattern of positioning those frequencies of $.9 \mathrm{kHz}$ and above was observed. Specifically, the tone bursts 3.2 and $4.8 \mathrm{kHz}$ were perceived as nearer the Ss' median sagittal plane than were .9 and $2.0 \mathrm{kHz}$. The latter frequencies, in turn, were perceived to originate nearer the median sagittal plane than were 1.4 and $7.2 \mathrm{kHz}$. Since, under conditions of binaural listening, some frequencies consistently appear further displaced toward the median sagittal plane than others (Butler, Roffler, \& Naunton, 1967), the possibility arose that subliminal stimuli impinging on the occluded ear may have influenced the results. Certainly stimuli whose intensities are below threshold value obtained by standard audiometric techniques can affect the perception of sounds delivered to the opposite ear (Groen, 1964; Butler \& Naunton, 1967). 
Table 1

The Number of Ss Out of 17 Who Perceived the Left-Listed Tonal Frequency to Originate Nearer the Midline Than Did the Right-Listed Tonal Frequency

\begin{tabular}{cc}
\hline Frequencies & $\begin{array}{c}\text { Number } \\
\text { of Ss }\end{array}$ \\
\hline $400<250$ & 11 \\
$600<400$ & 6 \\
$900<600$ & 15 \\
$1400<900$ & 12 \\
$2000<1400$ & 2 \\
$3200<2000$ & 3 \\
$4800<3200$ & 5 \\
$7200<4800$ & 0 \\
\hline
\end{tabular}

Accordingly, a patient totally deaf in one ear was given the same test, and he also was unable to locate most of the sound sources correctly. His placement of the tonal frequencies $.9 \mathrm{kHz}$ and above followed a pattern similar to that exhibited by the other five listeners. And, of course, in the case of this patient, no possibility of effective binaural stimulation existed.

In view of these preliminary data, it was considered worthwhile to undertake a more complete study of the apparent location of horizontally placed tonal stimuli heard monaurally.

\section{MAIN STUDY}

\section{Method}

Seventeen listeners not tested before served as Ss. Their hearing acuity was within normal limits. Only one loudspeaker was used, and this was concealed by draperies hung immediately behind the semicircular screen. The screen was painted white. Black numbers, 6 in. high, were spaced 10 deg apart, center to center, with respect to the listener's position. Number 1 was painted in the middle of the arc; Numbers 2-9 extended on each side of center.

The procedure involving occlusion of one ear and the obtaining of the thresholds and the instructions for reporting the location of sound sources were the same as those described in the pilot study. In this main experiment, however, Ss called out a number on the screen behind which they thought the sound originated, since no loudspeaker was visible. They were not told that just one loudspeaker was generating all the stimuli. The same tonal frequencies as those in the pilot study were used, and again the loudness level was 20 phons. As a rapid check on the in tegrity of the occlusion, all Ss were asked to block the unoccluded ear with their fingers, and then each frequency was presented at the original 20-phon level. No $S$ heard the sounds. In the present series of tests, stimulus rise-fall time was extended to $10 \mathrm{msec}$ and the stimulus plateau was lengthened to $50 \mathrm{msec}$. Interstimulus interval was $430 \mathrm{msec}$.

A trial consisted of a train of five stimuli fixed in frequency. Approximately $10 \mathrm{sec}$ elapsed between trials, during which time $S$ made known his location judgment and $\mathrm{E}$ recorded it. A total of 108 trials were given during a test session with each frequency being presented on 12 trials. Order of frequency presentation was haphazard. Ss were given three test sessions. A different listening condition was associated with each session. This was simply a precautionary measure. It served to confound the influence of any standing wave pattern that might have existed at the ear canal entrance due to the fact that the test room, although sound-treated, was nonetheless echoic. On the first test session, nine listeners faced the loudspeaker position and eight faced a point 80 deg removed from the loudspeaker. The situation was reversed for the second test session. When facing away from the loudspeaker, it was always on the side of the unoccluded ear. All listeners faced the loudspeaker position on the third test session. This time, however, the pinna of the unoccluded ear was pulled tightly forward by taping it to the listener's cheek.

\section{Results}

Almost without exception, Ss perceived all tonal frequencies to emanate from the side of the unoccluded ear. One $S$ perceived the three lower frequencies to come from the opposite side. If the concept of loudness difference can be extended to a monaural listening situation, loudness was the single cue available for localization. But here the information served only to distinguish the left from the right half of the total sound field. Binaural cues necessary for more exact localization within this segment of the sound field were not present. Still, most Ss perceived most stimuli as originating from a relatively restricted region in the horizontal plane. When questioned later, they admitted an uncertainty associated with many of the judgments, but there were only a few instances where a listener reported an inability to assign a location to a tone because of its diffuseness. And when this occured, it was confined to the low frequencies. Such trials were reinserted later in the test session and a judgment was always forthcoming.

The data for each test session were comparable (see Fig. 1); hence, statistical treatment of the results were carried out on pooled data. Listeners differed appreciably from one another with regard to where, on the side of the unoccluded ear, they perceived the location of the various tonal frequencies. This is evident

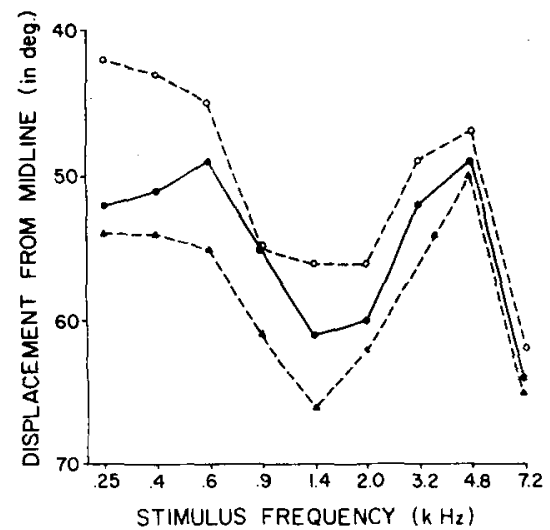

Fig. 1. Mean displacement from midline (median sagittal plane) of tone bursts as a function of stimulus frequency. Open circles/dashed line: $\mathbf{S}$ facing loudspeaker with pinna distorted. Closed circles/solid line: S facing loudspeaker. Closed triangles/dashed line: $\mathbf{S}$ facing $\mathbf{8 0} \mathrm{deg}$ from loudspeaker.

by the large standard deviations shown in Fig. 2. Yet, there was a considerable amount of agreement among listeners with regard to the relative position of one frequency with respect to another. When ranking the judged locations of the various tonal frequencies with respect to degrees from the S's median sagittal plane, the coefficient of concordance was .40 $(\mathrm{p}<.001)$. There was a bias similar to that observed in the pilot study for the relative position of frequencies of $.9 \mathrm{kHz}$ and above. Table 1 most clearly illustrates this fact. The third column in the table represents the number of Ss of 17 who perceived the tonal frequency listed in the

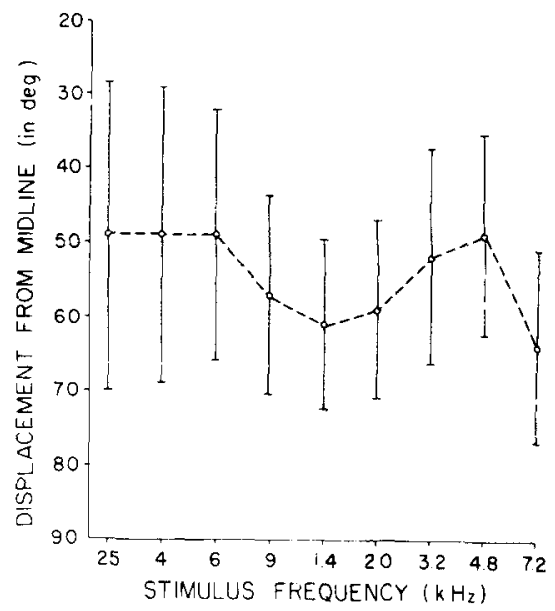

Fig. 2. Mean displacement from midline (median sagittal plane) of tone bursts as a function of stimulus frequency for pooled data. Vertical lines represent \pm 1 SD. 
first column to be nearer the median sagittal plane than the adjacent tonal frequency listed in the second column. For the lower frequencies, $.4 \mathrm{re} .25$ and $.6 \mathrm{re}$ $.4 \mathrm{kHz}$, the group was divided approximately in half with respect to whether its members perceived one tonal frequency as being nearer the median sagittal plane than the just lower-pitched frequency. But for the remaining frequencies, most, and in one instance, all members of the group perceived the spatial relations between adjacent frequencies in the same way. A chi-square test applied to the data in Table 1 indicated that the observed distribution of the listeners' perception of spatial relations between pairs of adjacent frequencies differed significantly $(\mathrm{p}<.001)$ from chance.

Some Ss remarked that the high-pitched frequencies appeared to originate above the numbers painted on the horizontally extended screen. Informal tests at the completion of the experiment indicated that the apparent vertical location of tone bursts with regard to their pitch was much more prominent under binaural listening conditions with the loudspeaker being positioned directly in front of the listener than under the conditions that obtained in this experiment.

\section{DISCUSSION}

It is most improbable that evolutionary pressure has been exerted on man or any other mammal to develop the capacity to locate tonal stimuli monaurally. Indeed, even binaural localization of tones is imprecise except when the sound source is directly ahead of the listener (Mills, 1958). That which is remarkably developed, certainly in man, is the capacity to discriminate between small differences in frequency. This capacity, which is utilized for distinguishing among complex sounds that differ slightly in frequency composition, is essential for effective verbal communication. The fact that tonotopic organization is a prominent feature of the mammalian auditory nervous system adds credence to the contention that frequency discrimination is basic to the auditory repertoire of mammals. With regard to the present study, the following questions arise: In the absence of relevant cues for localization, why should listeners perceive the various frequencies in a reasonably consistent spatial relation to one another? Why were the location judgments not randomly distributed? It is suggested that the observed spatial relation between adjacent frequencies was a by-product of the system's tonotopic organization. That the three lower frequencies bore no systematic spatial relation to one another is not considered embarrassing to this viewpoint; presmuably, low frequency tones are not processed by the nervous system in terms of the place principle.

This explanation, although devoid of functional significance, appears more adequate than others that can be advanced, such as (1) peculiarities of the sound field, (2) signal distortion brought about by relatively abrupt rise time, or (3) extrinsic associative cues. Differences among listening conditions confounded any peculiarities that the sound field might have had in common with the three test sessions; yet, the pattern of perceived locations was similar for the three conditions. No distortion products were audible; no doubt, they existed because of the relatively rapid onset of the tone bursts. Nevertheless, since the stimuli were presented at only 20 phons, the likelihood that signal distortion was responsible for the results is minimal. And even if they were responsible, it would be difficult to explain the observed pattern of spatial relations in this way. As was mentioned at the beginning of this paper, words associated with pitch do not have spatial connotations for sound sources originating in the horizontal plane. In view of the fact that a spatial arrangement was found among the different tonal frequencies in this plane, one wonders whether the spatial arrangement found previously for tones originating in the vertical plane can be attributed exclusively to associative cues. The basic organization of the auditory nervous system may play a role.

\section{REFERENCES}

ANGELL, 1. R. \& FITE, W. The monaural localization of sound. Psychological Review, 1901, 8, 225-246.

BUTLER, R. A., \& NAUNTON, R. F. The effect of stimulus sensation level on the directional hearing of unilaterally deafened persons. Journal of Auditory Research, 1967, 7, 15-23.

BUTLER, R. A., ROFFLER, S. K., \& NAUNTON, R. F. The role of stimulus frequency in the localization of sound in space. Journal of Auditory Research, 1967, 7, 169.180.

GROEN, 3. J. Super- and subliminal binaural beats. Acta Otolaryngologica, 1964, 57, 224-230.

MILLS, A. W. On the minimum audible angle. Journal of the Acoustical Society of America, $1958,30,237-246$.

PRATT, C. C. The spatial character of high and low tones. Journal of Experimental Psychology, 1930, 13, 278-285.

ROFFlER, S. K., \& BUTLER, R. A. Localization of tonal stimuli in the vertical plane. Journal of the Acoustical Society of America, 1968, 43, 1260-1266.

(Accepted for publication May 15, 1970.) 